\title{
Patient Financial Responsibility for Observation Care
}

\author{
Shreya Kangovi, MD, MS ${ }^{1,2,3 *}$, Susannah G. Cafardi, MSW, MPH4, Robyn A. Smith, BA ${ }^{1,3}$, Raina Kulkarni, BS ${ }^{3}$, \\ David Grande, MD, MPA ${ }^{1,2}$
}

\begin{abstract}
${ }^{1}$ Department of Medicine, University of Pennsylvania Perelman School of Medicine, Philadelphia, Pennsylvania; 'Leonard Davis Institute of Health Economics, University of Pennsylvania, Philadelphia, Pennsylvania; ${ }^{3}$ Penn Center for Community Health Workers, Philadelphia, Pennsylvania; ${ }^{4}$ Centers for Medicare \& Medicaid Services, Baltimore, Maryland.
\end{abstract}

BACKGROUND: As observation care grows, Medicare beneficiaries are increasingly likely to revisit observation care instead of being readmitted. This trend has potential financial implications for Medicare beneficiaries because observation care-although typically hospital based-is classified as an outpatient service. Beneficiaries who are readmitted pay the inpatient deductible only once per benefit period. In contrast, beneficiaries who have multiple care episodes under observations status are subject to coinsurance at every stay and could accrue higher cumulative costs.

OBJECTIVES: We were interested in answering the question: Do Medicare beneficiaries who revisit observation care pay more than they would have had they been readmitted?

DESIGN: We used a $20 \%$ sample of the Medicare Outpatient Standard Analytic File (2010-2012) to determine the total cumulative financial liability for Medicare beneficiaries who revisit observation care multiple times within a 60-day period.
PARTICIPANTS: Participants were fee-for-service Medicare beneficiaries who had Part A and Part B coverage for a full calendar year (or until death) during the study period.

MEASUREMENTS: Our primary measure was beneficiary financial responsibility for facilities fees.

RESULTS: On average, beneficiaries with multiple observation stays in a 60-day period had a cumulative financial liability of $\$ 947.40$ (803.62), which is significantly lower than the $\$ 1100$ inpatient deductible $(P<0.01)$. However, $26.6 \%$ of these beneficiaries had a cumulative financial liability that exceeded the inpatient deductible.

CONCLUSIONS: More than a quarter of Medicare beneficiaries with multiple observation stays in a 60-day time period have a higher financial liability than they would have had under Part A benefits. Journal of Hospital Medicine 2015;10:718-723. (c) 2015 Society of Hospital Medicine
When Medicare beneficiaries seek healthcare, they are increasingly likely to have that care delivered under observation status. From 2006 to 2010, the annual number of observation hours for Medicare beneficiaries rose by nearly $70 \% .^{1}$ In 2012 , the number of observation stays for Medicare beneficiaries reached 1.5 million. $^{2}$ One consequence of this trend is a potential change in patient financial liability-the amount patients are expected to pay out of pocket for care. Although observation care is usually delivered in a hospital, Medicare classifies it as an outpatient service, covered through Part B rather than inpatient Part A. In two-thirds of US hospitals, observation care is largely an administrative classification, delivered in the same units and beds as "admitted" patients rather than in a protocol-driven observation care unit. ${ }^{3}$ Therefore, patients are often unaware of their outpatient observation status and its financial implications until they receive their hospital bill.

\footnotetext{
*Address for correspondence and reprint requests: Shreya Kangovi, MD, 1233 Blockley Hall, 423 Guardian Dr., Philadelphia, PA 19104; Telephone: 215-520-5309; Fax: 215-573-2742;

E-mail: kangovi@mail.med.upenn.edu

Additional Supporting Information may be found in the online version of this article.

Received: February 12, 2015; Revised: June 16, 2015; Accepted: June 22, 2015

2015 Society of Hospital Medicine DOI 10.1002/jhm.2436

Published online in Wiley Online Library (Wileyonlinelibrary.com).
}

Observation has the potential to impact patient financial liability through 4 mechanisms. ${ }^{4}$ First, instead of a fixed cost for an inpatient admission (eg, a fixed deductible for a hospital admission), patients pay a percentage of the cost of each service provided. Therefore, patients who have long observation stays or receive expensive services could have higher than expected liability. A recent study using all-payer data demonstrated that patients with longer observation stays (greater than 24 hours) paid $21 \%$ more than for those with shorter stays. ${ }^{5}$

A second consideration is that Medicare does not cover the same hospital services for observation care as it does for inpatient care. For example, self-administered medications are generally not covered for beneficiaries receiving observation care. However, the Office of the Inspector General $(\mathrm{OIG})^{2}$ recently found that the average patient cost per observation stay in 2012-even including the cost of self-administered medications-was $\$ 528$. This was significantly lower than the inpatient deductible (\$1156 in 2012) that patients would have paid had they been admitted. Although on average patients paid less for observation care, the OIG report found that $6 \%$ of observation stays were more costly to patients than inpatient admissions.

Third, there are certain benefits that Medicare beneficiaries are not eligible for unless they are admitted to the hospital. For a beneficiary to receive skilled nursing facility (SNF) benefits, they must be admitted to 
the hospital for 3 or more days. This was the basis for Bagnall $v$ Sebelius, a class action lawsuit against the Centers for Medicare \& Medicaid Services (CMS) filed in 2009 by the Center for Medicare Advocacy. ${ }^{6}$ The OIG estimated that in 2012, Medicare beneficiaries had 600,000 observation stays longer than 3 days that failed to qualify them for SNF services. Since then, CMS created the "2-midnight rule," stating that CMS will assign inpatient status to all medically necessary stays of 2 midnights or longer. This rule was intended, in part, to curb the use of observation stays greater than 48 hours and was a key factor in Judge Michael Shea's decision to dismiss Bagnall $v$ Sebelius. ${ }^{6}$

Finally, Medicare beneficiaries who must revisit the hospital may have greater cumulative costs under observation care versus inpatient care. Medicare beneficiaries are partially protected from accumulating high costs over multiple inpatient admissions by a benefit design known as the benefit period. A benefit period begins the day a beneficiary is admitted to a hospital or SNF, and ends when he or she has not received any inpatient hospital or SNF care for 60 days in a row. Beneficiaries pay the inpatient deductible only once per benefit period, even if they have multiple readmissions during this time. So, for example, if a beneficiary was readmitted to the hospital 59 days after discharge, he or she would not have to pay the inpatient deductible again. In addition, the benefit period would be extended for an additional 60 days. In contrast, beneficiaries who receive observation care are subject to coinsurance at every subsequent visit; therefore, these beneficiaries could accrue high cumulative costs over multiple observation stays.

To our knowledge, there have been no published studies focusing on the potentially vulnerable population of Medicare beneficiaries who frequently use observation care. Our objectives were to determine the financial liability for patients who have multiple observation stays within a 60-day period, and then compare this to the inpatient deductible they would have paid as inpatients.

\section{METHODS}

\section{Data Sources}

We used a $20 \%$ sample of the Medicare Outpatient Standard Analytic File (SAF) to identify hospital observation stays among beneficiaries over the 3 -year period 2010 to 2012. The Outpatient SAF contains all institutional outpatient claims filed on the UB-04 form. We also used publicly available data (American Association of Medical Colleges Council of Teaching Hospitals status, ${ }^{8}$ US Department of Agriculture rural/urban continuum codes, ${ }^{9}$ CMS Hospital Cost Reports, ${ }^{10}$ and census bureau region) to link hospital Medicare provider number to hospital characteristics.

\section{Measures}

Our primary measure was beneficiary financial responsibility for facilities fees. For observation care patients, this amount is the sum of the Part B coinsurance liability amount, the Part B deductible amount, and the blood deductible liability amount. ${ }^{11}$

Observation care claims also include information on claim date, hospital Medicare provider number, principal diagnosis (International Classification of Diseases, Ninth Revision codes), services provided, and total hours for which observation services were provided (service units). Finally, claims include unique individual identifiers, which allowed us to construct our study population and obtain beneficiary characteristics including beneficiary age, race, gender, dual eligibility for Medicare/Medicaid, and severity of illness as measured by the CMS Hierarchical Condition Category (CMS-HCC). ${ }^{12}$ We obtained publicly available data on hospital characteristics, including academic hospital status, ${ }^{8}$ urban versus rural, ${ }^{9}$ nonprofit versus for profit, ${ }^{10}$ and census bureau region, and linked these to the hospital Medicare provider number.

\section{Study Sample and Statistical Analysis}

We first created a denominator file that included all feefor-service Medicare beneficiaries who had Part A and Part B coverage for a full calendar year (or until death) during the study period 2010 to 2012 . We included dually eligible individuals, provided they had fee-for-service Medicare rather than a Medicare Advantage Plan.

We then constructed our study sample of unique beneficiaries who had an observation stay (lasting $\geq 8$ hours, which is the criteria for Medicare payment) during the study period. We identified observation stays using revenue center codes and the Healthcare Common Procedure Coding System classification, and according to coding instructions found in the Medicare Claims Processing Manual. ${ }^{13}$ Beneficiaries were excluded if their stay was converted from observation to inpatient status, because these claims may not be reliably tracked. After creating this study sample, we calculated the mean financial liability for the first observation stay for each beneficiary.

Next, within our study sample, we divided beneficiaries receiving observation care into 2 groups: those with multiple visits (defined as $\geq 2$ observation stays in any 60-day interval over the study period) and those without multiple visits. For each beneficiary with multiple visits, we calculated the mean cumulative financial liability for all stays within the 60-day interval. We then compared this mean cumulative financial liability to the 2010 inpatient deductible of $\$ 1100$.

We compared baseline characteristics of Medicare beneficiaries not receiving observation care, those with multiple observation visits, and those without multiple visits. We did this by using $\chi^{2}$ tests for categorical variables, 2-tailed unpaired $t$ tests for 2-way comparisons 
TABLE 1. Beneficiary Characteristics $(n=7,470,676)$

\begin{tabular}{|c|c|c|c|c|}
\hline & \multirow[b]{2}{*}{$\begin{array}{l}\text { Medicare FFS Beneficiaries } \\
\text { Not Receiving Observation Care }\end{array}$} & \multicolumn{2}{|c|}{ Observation Care $(n=691,760)$} & \multirow[b]{2}{*}{$P$ Value } \\
\hline & & $\begin{array}{l}\text { No Multiple Observation } \\
\text { Stays in } 60 \text { Days }\end{array}$ & $\begin{array}{l}\text { Multiple }(\geq 2) \text { Observation } \\
\text { Stays in } 60 \text { Days }\end{array}$ & \\
\hline Age, y, mean (SD) & $70.5(12.9)$ & $72.2(13.1)$ & $70.3(14.9)$ & $<0.01$ \\
\hline Gender, no. ( $(\%)$ & & & & $<0.01$ \\
\hline Male & $3,720,428(54.9)$ & $387,333(59.6)$ & $24,462(59.1)$ & \\
\hline Female & $3,058,488(45.1)$ & $263,042(40.4)$ & $16,923(40.9)$ & \\
\hline Race, no. (\%) & & & & $<0.01$ \\
\hline White & $5,673,580(83.7)$ & $545,165(83.8)$ & 33,586 (81.2) & \\
\hline Black & $674,420(10.0)$ & $74,367(11.4)$ & $5,913(14.3)$ & \\
\hline Other & $430,916(6.4)$ & $30,843(4.7)$ & $1,886(4.6)$ & \\
\hline Average no. of chronic conditions, mean (SD) & $1.7(1.7)$ & $2.8(2.0)$ & $3.6(2.1)$ & $<0.01$ \\
\hline Length of stay, h, mean (SD) & $N / A$ & $29.9(53.7)$ & $32.1(16.9)$ & $<0.01$ \\
\hline Most common hospital diagnoses, no. $(\%)^{*}$ & & & & N/A \\
\hline Other chest pain (786.59) & $N / A$ & $82,550(12.7)$ & $9,995(11.5)$ & \\
\hline Chest pain, unspecified (786.50) & $N / A$ & $56,416(8.7)$ & $7,578(8.7)$ & \\
\hline Syncope and collapse (780.2) & $N / A$ & $34,183(5.3)$ & $3,291(3.8)$ & \\
\hline Coronary atherosclerosis (414.01) & $N / A$ & $16,348(2.5)$ & $2,763(3.1)$ & \\
\hline
\end{tabular}

NOTE: The denominator file includes all unique FFS Medicare beneficiaries with Part A and B coverage for a full calendar year. Observation care users were beneficiaries who had an observation stay ( $\geq 8$ hours), excluding those whose stay converted to inpatient status. Abbreviations: FFS, fee-for-service, N/A, not applicable; SD, standard deviation. *Numbers represent total number of times these diagnoses were listed across all stays. Therefore, percent represents an event rate and may include recurrent diagnoses for the same individual.

of means, and analysis of variance for 3-way comparisons of means. We compared our primary outcome, mean beneficiary financial liability with the inpatient deductible of $\$ 1100$ using a 1 -sample $z$ test. As an exploratory analysis, we compared characteristics of beneficiaries with multiple observation visits with high cumulative liability $(>\$ 1100)$ versus low liability using bivariate analyses. We then created a multivariable logistic regression model for high liability. All analyses were performed using SAS version 9.1 (SAS Institute, Inc., Cary, NC). This study was reviewed by the institutional review board of the University of Pennsylvania.

\section{RESULTS}

Of the 7,470,676 unique Medicare beneficiaries in the $20 \%$ denominator file, $691,760(9.3 \%)$ had at least 1 observation visit during the 3-year study period (Table 1 ). The proportion of beneficiaries using observation care rose in each year of the study; $4.1 \%$ of beneficiaries used observation care in 2010, $4.4 \%$ in 2011, and $5.0 \%$ in 2012 .

Of the beneficiaries receiving observation care over the entire study period, $41,385(6.0 \%)$ had multiple visits ( $\geq 2$ observation visits in any 60 -day interval). The number of beneficiaries with multiple visits grew by $21.9 \%$ from 2010 to 2012 . There were racial differences in the use of observation care; patients with multiple visits were more likely to be black than those without multiple visits or those not receiving observation care $(14.3 \%$ vs $11.4 \%$ vs $10.0, P<0.01)$. Multiple observation visits were also associated with a higher number of chronic conditions (3.6 vs 2.8 vs 1.7, $P<0.01$ ) (Table 1).
The mean financial liability for the first observation stay for each beneficiary in our study sample was $\$ 469.42$ (442.43) (Table 2). This is significantly lower than the standard inpatient deductible of $\$ 1100$ $(\mathrm{p}<0.01)$. For $9.2 \%$ of beneficiaries, the financial liability was greater than the inpatient deductible.

The cumulative mean financial liability for beneficiaries with $\geq 2$ stays in a 60-day interval was $\$ 947.40$ (803.62) (Table 2). This is significantly lower than the standard inpatient deductible of $\$ 1100(P<$ 0.01 ). However, for $26.6 \%$ of beneficiaries, cumulative financial liability was greater than the $\$ 1100$ inpatient deductible, which is what they would have paid had these hospital visits been inpatient admissions (Figure 1).

There were several factors associated with having this excess cumulative liability (Table 3 ). Higher frequency of observation visits within a 60-day period was associated with high liability (odds ratio [OR]: 2.0, 95\% confidence interval [CI]: 1.9-2.1). In addition, having an index hospitalization in the Northeast region of the country was associated with lower odds of being in the high-liability group (OR: 0.51, 95\% CI: 0.47-0.55). High liability was weakly associated with lower CMS-HCC risk scores, non-dual eligibility, non-black race, and index hospital stay at an academic, urban, or nonprofit hospital.

\section{DISCUSSION}

Our findings suggest that for $91 \%$ of Medicare beneficiaries, a single observation stay was less costly than an inpatient admission. However, when beneficiaries had to return to observation care within 60 days of a prior stay, on average, their cumulative costs went up to $\$ 947$. For more than a quarter of beneficiaries with 
TABLE 2. Patient Financial Responsibility

\begin{tabular}{|c|c|c|c|c|c|c|}
\hline & Mean (SD) & 25th Percentile & 50th Percentile & 75th Percentile & 90th Percentile & 99th Percentile \\
\hline First observation stay, $n=691,760$ & $\$ 469.43(442.43)$ & $\$ 216.20$ & $\$ 333.77$ & $\$ 529.87$ & $\$ 1,045.85$ & $\$ 2,088.66$ \\
\hline $\begin{array}{c}\text { Cumulative } 60 \text { days for beneficiaries } \\
\text { with multiple visits, } n=41,385\end{array}$ & $\$ 947.40(803.62)$ & $\$ 471.01$ & $\$ 681.40$ & $\$ 1,152.66$ & $\$ 1,904.54$ & $\$ 3,902.50$ \\
\hline
\end{tabular}

NOTE: Abbreviations: SD, standard deviation.

multiple observation visits, the cumulative costs of these observation visits exceeded the inpatient deductible.

The results of this study are consistent with prior studies of observation care. We found that in 2010, $4.1 \%$ of Medicare beneficiaries used observation care, consistent with the estimated $4.0 \%$ in 2009 reported by the AARP Public Policy Institute. ${ }^{14}$ Also, consistent with the growth rate from the AARP report, we found growth in use of observation care from $4.1 \%$ in 2010 to $5.0 \%$ in 2012 . We found that the mean length of stay for observation care was 30 hours, consistent with recent studies estimating mean length of stay in 2009 as 25.9 hours. $^{15}$ We found that beneficiaries paid an average of $\$ 468.50$ per observation care stay, very close to the $\$ 401$ estimated by the 2013 OIG report (when self-administered drugs were excluded). ${ }^{2}$ The difference may be explained by the fact that OIG included observation stays of $<8$ hours in their sample; we excluded these stays because they did not meet criteria for Medicare payment. Like the OIG report, we also found that the vast majority (91\%) of beneficiaries pay less for any given observation stay than for an inpatient stay.

However, our findings raise the concern that for a significant proportion of beneficiaries who are likely to return to the hospital, cumulative costs of multiple observation stays may be greater than the inpatient deductible. Therefore, although observation care is, on average, less expensive for beneficiaries than inpatient admission, beneficiaries lack the protection from escalating financial liability over multiple visits.

This finding is worrisome for 3 reasons. First, compared with the general beneficiary population, Medicare beneficiaries who return to the hospital frequently are also typically of lower socioeconomic status ${ }^{16-18}$ and may be disproportionately affected by any increased financial liability. Interestingly, our analysis showed that patients with high financial liability incurred from multiple observation stays actually had a lower comorbidity burden than patients in the multiple

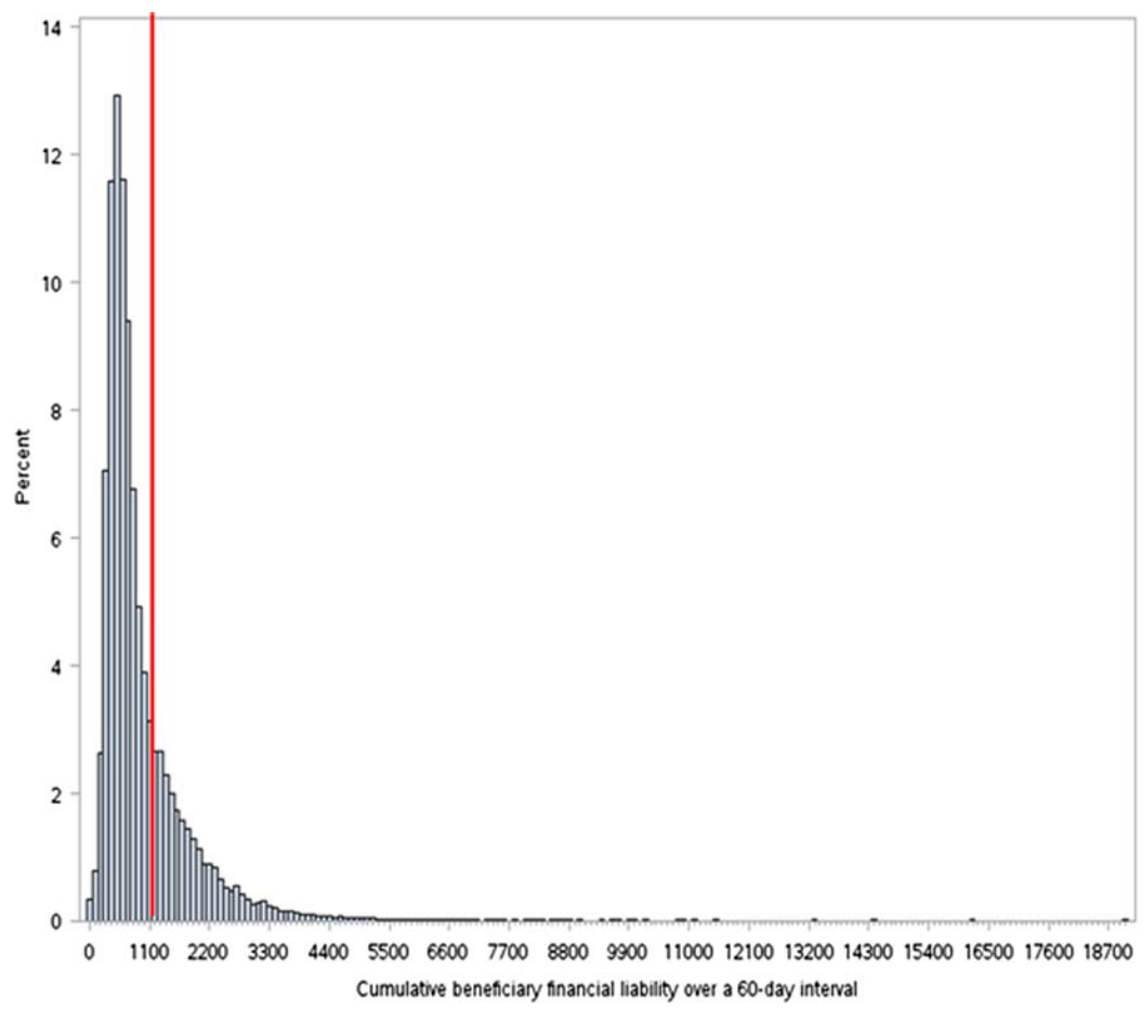

FIG. 1. Distribution of cumulative financial liability for beneficiaries with multiple observation care visits over a $60-$ day interval. Of the beneficiaries, $26.6 \%$ have cumulative costs greater than the 2010 inpatient deductible of $\$ 1100$. 
TABLE 3. Characteristics of Low- Versus High-Liability Beneficiaries $(n=41,385)^{\star}$

\begin{tabular}{|c|c|c|c|c|}
\hline & \multicolumn{3}{|c|}{ Unadjusted } & \multirow{2}{*}{$\frac{\text { Adjusted }}{\text { OR }(95 \% \mathrm{Cl})}$} \\
\hline & Low, $n=30,416$ & High, $n=10,969$ & $P$ Value & \\
\hline №. of observation visits in a 60-day period, mean (SD) & $2.08(0.30)$ & $2.18(0.52)$ & $<0.001$ & $2.0(1.9-2.1)$ \\
\hline \multirow[t]{3}{*}{ Most common hospital diagnoses, no. $(\%)^{\dagger}$} & Chest pain (other or unspecified); 13,381 (21.1\%) & Chest pain (other or unspecified); 4,165 (17.4\%) & N/A & \\
\hline & Syncope and collapse; 2,602 (4.1\%) & Coronary atherosclerosis; 2,228 (9.3\%) & $N / A$ & \\
\hline & Dehydration; 1,264 (2.0\%) & Syncope and collapse; 686 (2.9\%) & N/A & \\
\hline Dual eligibility, no. $(\%)^{\frac{1}{+}}$ & $10,895(35.8 \%)$ & $3,162(28.8 \%)$ & $<0.001$ & $0.76(0.73-0.80)$ \\
\hline Race, no. $(\%)$ & & & $<0.001$ & \\
\hline White & $24,283(79.8 \%)$ & $9,303(84.8 \%)$ & & 1 \\
\hline Black & $4,704(15.5 \%)$ & $1,209(11.0 \%)$ & & $0.79(0.73-0.85)$ \\
\hline Other & $1,429(4.7 \%)$ & $457(4.2 \%)$ & & $0.95(0.85-1.1)$ \\
\hline Hospital census bureau region, no. $(\%)^{\S}$ & & & $<0.001$ & \\
\hline Urban hospital & $13,260(44.4 \%)$ & $3,926(37.1 \%)$ & $<0.001$ & $0.79(0.76-0.83)$ \\
\hline Nonprofit hospital & $20,665(69.2 \%)$ & $7,143(67.4 \%)$ & 0.001 & $0.89(0.83-0.94)$ \\
\hline
\end{tabular}

NOTE: Abbreviations: $\mathrm{CHF}$, congestive heart failure; $\mathrm{Cl}$, confidence interval; $\mathrm{HCC}$, Hierarchical Condition Category; N/A, not applicable; OR, odds ratio. *Low liability defined as less than or equal to inpatient deductible. 'Numbers represent total number of times these diagnoses were listed across all stays. Therefore, percent represents an event rate and may include recurrent diagnoses for the same individual, which precludes bivariate comparison. eligibility defined as having Medicaid eligibility for 10 of the 12 months of the year of services. \$Hospital characteristics (census bureau region, academic, urban, nonprofit) pertain to index hospital.

observation stay group with lower liability, and were less likely to be black or dual eligible. This finding perhaps reflects the fact that very high-risk patients who returned to the hospital were readmitted rather than being placed under observation status again, potentially depleting the high-liability group of patients with these high-risk characteristics. Second, patients have little control over their classification as observation versus inpatients. In many hospitals, observation is simply an administrative classification for care that-from the patients' perspective-is identical to inpatient care. ${ }^{4}$ It is problematic to expose patients to varying financial liability based on differences in administrative classification. Finally, we found that the number of patients with multiple observation visits within a 60 -day period rose by $22 \%$ between 2010 and 2012 . This means that the problem of excess cumulative financial liability is likely to be increasingly common over the coming years. The increased incidence of multiple observation visits may be simply related to overall increases in use of observation care. Alternatively, some authors worry that this trend may be driven by hospital use of observation care for patients who are likely to be readmitted. ${ }^{14,19}$ A recent analysis by Gerhardt et al. ${ }^{20}$ did not find evidence of direct substitution of observation care in the 30-day window after an index admission. This suggests that physicians are not explicitly shifting patients to observation care in order to "avert" a readmission and the readmissions penalty. ${ }^{21}$ However, it does not exclude the possibility of general shifts toward observation care for patients likely to return.
Experts have suggested capping the total out-of-pocket expense for observation care at the inpatient-deductible amount. ${ }^{4}$ This deductible cap would prevent the relatively rare case in which a single observation stay costs more than an inpatient admission. Our findings suggest that a benefit period (as in Part A) during which such a deductible would serve as a cap would also protect a small but significantly impacted population from higher than expected cumulative costs for multiple observation care visits.

This study has several limitations. First, we are only able to measure beneficiary financial responsibility and not the amount actually paid. This can differ from financial responsibility when patients do not pay their bill, when patients accrue additional charges (such as self-administered medications) that are not reflected on outpatient claims, or when patients have additional third-party payers who cover part or all of the financial responsibility (as with dually eligible patients). For such beneficiaries with supplemental coverage, outof-pocket cost in both scenarios (inpatient or observation care) may be low or zero. However, the use of financial responsibility as an approximation of actual payment amounts is recommended by the Research Data Assistance Center and is consistent with other studies of cost in observation care. ${ }^{2}$ Second, our data source only allowed us to assess facilities fees and not professional expenses. Our comparator of the inpatient deductible also only reflects facilities fees, making this a valid comparison. Third, we selected 60 days as the time interval for defining multiple visits. This interval is 
intended to approximate a Medicare benefit period, which is the time interval following a discharge from a hospital or an SNF until the time when the deductible resets. However, Medicare actually extends the benefit period another 60 days if a patient is readmitted during that 60 -day period. Thus, 60 days is actually the shortest possible benefit period. By conservatively defining the interval for recurrent observation stays in this way, we are likely underestimating the number and cost of observation stays in a true benefit period, and biasing our results toward the null.

In conclusion, our findings suggest that a significant proportion of Medicare beneficiaries who revisit observation care pay more than they would have had they been readmitted. As CMS policies on observation care continue to evolve, it may be helpful to consider measures to cap total out-of-pocket expenses within a benefit period to protect beneficiaries from higher than expected costs.

Disclosure: Nothing to report.

\section{References}

1. June 2012 Data Book: Health Care Spending and the Medicare Program. Washington, DC: Medicare Payment Advisory Commission; 2012.

2. Wright $\mathrm{S}$. Hospitals' use of observation stays and short inpatient stays for Medicare beneficiaries, OEI-02-12-00040. Washington, DC: Department of Health and Human Services, Office of the Inspector General; 2013.

3. Wiler JL, Ross MA, Ginde AA. National study of emergency department observation services. Acad Emerg Med. 2011;18(9):959-965.

4. Baugh CW, Schuur JD. Observation care-high-value care or a costshifting loophole? N Engl J Med. 2013;369(4):302-305.

5. Hockenberry JM, Mutter R, Barrett M, Parlato J, Ross MA. Factors associated with prolonged observation services stays and the impact of long stays on patient cost. Health Serv Res. 2014:49(3):893-909.

6. Bagnallv Sebelius. No. 3:11cv1703 (MPS). September 23, 2013.

7. Centers for Medicare \& Medicaid Services. Final Rule CMS-1599-F: Discussion of the Hospital Inpatient Admission Order and Certification; 2 Midnight Benchmark for Inpatient Hospital Admissions. CMS-
1599-F2013.2013. Available at: http://www.cms.gov/Outreach-andEducation/Outreach/OpenDoorForums/Downloads/02042014SODF. pdf. Accessed June 16, 2015

8. Council of Teaching Hospitals and Health Systems (COTH). Association of American Medical Colleges website. Available at: https:// www.aamc.org/members/coth/. Accessed May 5, 2006.

9. United States Department of Agriculture Economic Research Service. Rural-urban continuity codes. Available at: http://www.ers.usda.gov/ data-products/rural-urban-continuum-codes.aspx. Accessed June 16, 2015.

10. Centers for Medicare \& Medicaid Services. Cost reports. Available at: https://www.cms.gov/Research-Statistics-Data-and-Systems/DownloadablePublic-Use-Files/Cost-Reports/?redirect=/costreports. Accessed June 16, 2015

11. Payment calculation: hospital outpatient SAF. Minneapolis, MN; 2013

12. Li P, Kim MM, Doshi JA. Comparison of the performance of the CMS Hierarchical Condition Category (CMS-HCC) risk adjuster with the Charlson and Elixhauser comorbidity measures in predicting mortality. BMC Health Serv Res. 2010;10:245.

13. American Medical Association. 2006 Medicare physician payment update and claims processing-questions and answers. J Okla State Med Assoc. 2006;99(3):136.

14. Zhao Lan, Schur C, Kowlessar N, Lind KD. AARP report: rapid growth in medicare hospital observation services: what's going on? Available at: http://www.aarp.org/content/dam/aarp/research/public_policy_institute/ health/2013/rapid-growth-in-medicare-hospital-observation-servicesAARP-ppi-health.pdf. Accessed June 16, 2015.

15. Wright B, Jung HY, Feng Z, Mor V. Hospital, patient, and local health system characteristics associated with the prevalence and duration of observation care. Health Serv Res. 2014;49(4):1088-1107.

16. Baker DW, Gazmararian JA, Williams MV, et al. Functional health literacy and the risk of hospital admission among Medicare managed care enrollees. Am J Public Health. 2002;92(8):1278-1283.

17. Elixhauser A, Au DH, Podulka J. Readmissions for chronic obstructive pulmonary disease, 2008: statistical brief 121. Rockville, MD: Healthcare Cost and Utilization Project; 2011.

18. Rodriguez-Artalejo F, Guallar-Castillon P, Herrera MC, et al. Social network as a predictor of hospital readmission and mortality among older patients with heart failure. J Card Fail. 2006;12(8):621-627.

19. Feng Z, Wright B, Mor V. Sharp rise in Medicare enrollees being held in hospitals for observation raises concerns about causes and consequences. Health Aff (Millwood). 2012;31(6):1251-1259.

20. Gerhardt G, Yemane A, Apostle K, Oelschlaeger A, Rollins E, Brennan N. Evaluating whether changes in utilization of hospital outpatient services contributed to lower Medicare readmission rate. Medicare Medicaid Res Rev. 2014;4(1).

21. Centers for Medicare \& Medicaid Services. CMS-1518-P, CMS-1518$\mathrm{CN}$ and CMS-1518-CN2. Proposed rule and correction notice: Available at: http://www.cms.gov/Medicare/medicare-fee-for-service-payment/ acuteinpatientPPS/readmissions-reduction-program.html. Accessed June $16,2015$. 